\title{
299 BROAD T ANTIGEN-SPECIFIC CD8+ T CELL REPERTOIRE IS ASSOCIATED WITH RESPONSE TO PD-1 BLOCKADE IN VIRUS POSITIVE MERKEL CELL CARCINOMA
}

${ }^{1}$ Ulla Hansen*, ${ }^{2}$ Candice Church, ${ }^{1}$ Amalie Bentzen, ${ }^{3}$ Steven Fling, ${ }^{3}$ Nirasha Ramchurren, ${ }^{4}$ Suzanne Topalian, ${ }^{2}$ Paul Nghiem, ${ }^{1}$ Sine Hadrup. ${ }^{1}$ Technical University of Denmark, Kgs. Lyngby, Denmark; ${ }^{2}$ University of Washington, Seattle, USA; ${ }^{3}$ Fred Hutchinson Cancer Research Center, Seattle, WA, USA; ${ }^{4}$ Johns Hopkins University School of Med., Baltimore, $M D, U S A$

Background Merkel cell carcinoma (MCC) is an aggressive human skin cancer primarily induced by Merkel Cell Polyomavirus (MCPyV) driven by expression of the oncogenic $\mathrm{T}$ antigens (T-Ags): Large $\mathrm{T}$ and Small $\mathrm{T}$ antigen. Checkpoint inhibition therapy blocking the programmed cell death protein-1 (PD-1) pathway has proven effective with a clinical response rate up to $58 \%,{ }^{1}$ highlighting the critical role of immune surveillance for tumor control. Yet, evidence for the impact of $\mathrm{T}$-Ag-specific $\mathrm{T}$ cells following immunotherapy is still limited.

Methods Potential CD8 $+\mathrm{T}$ cell epitopes derived from the TAgs and the Viral capsid protein 1 (VP1) were predicted with netMHCpan 4.0 as 9- and 10-mer peptides with a rank score $<2$ for binding to 33 different HLA class I types. Peripheral blood mononuclear cells (PBMC) were obtained from 24 $\mathrm{MCPyV}+\mathrm{MCC}$ patients prior and post anti-PD-1 therapy initiation (CITN-09/Keynote-017). $T$ cell recognition of the MCPyV-derived peptides during therapy was evaluated using the high-throughput technology of DNA barcode labeled pMHC multimers. Phenotypic characteristics of multimer-binding $\mathrm{T}$ cells were evaluated for selected patients.

Results Across all patients, 40 T-Ag-specific CD8 + T-cell populations were detected recognizing 31 epitopes restriction to 14 different HLA class I types. T-Ag-specific CD8 $+\mathrm{T}$ cells were detected in responders (complete and partial response, $\mathrm{n}=17$ ) during therapy with a trend of increased number of responses observed after therapy initiation. Whereas only a single T-Ag-specific population was detectable in non-responders (stable and progressive disease, $\mathrm{n}=7$ ). Moreover, the $\mathrm{T}$ cell repertoire after therapy initiation was significantly increased in the responder group compared to non-responder with the TAg-specific $\mathrm{T}$ cells showing an activated effector memory phenotype.

Conclusions The current study indicates that the T-Ag-specific $\mathrm{T}$ cells are associated with clinical benefit to checkpoint inhibitor therapy. Furthermore, the broad identification of novel TAg-derived $\mathrm{T}$ cell epitopes could potentially facilitate the use of targeted $\mathrm{T}$ cell therapy to enhance $\mathrm{T}$ cell recognition and clearance of MCC in combination with checkpoint inhibition.

Acknowledgements Supported by the Cancer Immunotherapy Trials Network (CITN)

\section{REFERENCE}

1. Nghiem P, Bhatia S, Lipson E. Three-year survival, correlates and salvage therapies in patients receiving first-line pembrolizumab for advanced Merkel cell carcinoma. J Immunother cancer 2021;9:e002478.

http://dx.doi.org/10.1136/jitc-2021-SITC2021.299 